\title{
Commentary: Role of Sterylglucosidase 1 (Sgl1) on the pathogenicity of Cryptococcus neoformans: potential applications for vaccine development
}

\author{
Luis R. Martinez * \\ Department of Biomedical Sciences, New York Institute of Technology College of Osteopathic Medicine, New York Institute of \\ Technology, Old Westbury, NY, USA
}

Keywords: Cryptococcus neoformans, glycolipids, sterylglucosidase, T cells, vaccines

\section{A commentary on}

\section{OPEN ACCESS}

Edited by:

Helio K. Takahashi,

Universidade Federal de São Paulo,

Brazil

Reviewed by:

Marcos Sergio Toledo,

Universidade Federal de São Paulo,

Brazil

Anderson Messias Rodrigues, Federal University of São Paulo, Brazil

${ }^{*}$ Correspondence:

Luis R. Martinez

Imarti13@nyit.edu

Specialty section:

This article was submitted to

Fungi and Their Interactions,

a section of the journal

Frontiers in Microbiology

Received: 28 August 2015

Accepted: 25 September 2015

Published: 09 October 2015

Citation:

Martinez LR (2015) Commentary: Role of Sterylg/ucosidase 1 (Sgl1) on the

pathogenicity of Cryptococcus neoformans: potential applications for

vaccine development.

Front. Microbiol. 6:1112.

doi: 10.3389/fmicb.2015.01112
Role of Sterylglucosidase 1 (Sgl1) on the pathogenicity of Cryptococcus neoformans: potential applications for vaccine development

by Rella, A., Mor, V., Farnoud, A. M., Singh, A., Shamseddine, A. A., Ivanova, E., et al. (2015). Front. Microbiol. 6:836. doi: 10.3389/fmicb.2015.00836

Cryptococcosis is an opportunistic fungal infection associated with AIDS. Differences in the clinical manifestations of cryptococcosis have been observed among encapsulated Cryptococcus species, with neoformans strains mostly isolated from individuals with impaired immunity (Dromer et al., 1994) and gattii strains from immunocompetent hosts (Speed and Dunt, 1995). This medically important fungus is globally distributed resulting in clinical disease in approximately $30 \%$ of HIV infected individuals mainly in areas such as South East Asia and sub-Saharan Africa (Powderly, 1993). Cryptococcossis is acquired after airborne fungi in the form of desiccated or poorly encapsulated yeast cells or as basidiospores enter the host by inhalation (Neilson et al., 1977; Levitz, 1991) resulting in asymptomatic disease or dormant infections. Progression toward pulmonary and systemic disease commonly occurs in individuals with severely compromised immune responses. There are 1 million cases of cryptococcal meningitis each year worldwide, resulting in approximately 600,000 deaths (Park et al., 2009).

C. neoformans infection presents formidable problems for the host immune response, including the presence of titan cells in tissue (Zaragoza and Nielsen, 2013), a lack of antibody responsiveness to capsular polysaccharide, and extensive accumulation of polysaccharide in tissue (Goldman et al., 1995). The presence of glucuronoxylomannan (GXM), the main capsular polysaccharide of C. neoformans, in tissue seems to be the most important contributor to the fungus pathogenesis given that the capsule is abundantly shed during infection and has been associated with immunosuppressive effects (Vecchiarelli, 2000), including an increase in HIV load (PettoelloMantovani et al., 1992) and cellular infectivity (Pettoello-Mantovani et al., 1994).

Despite its clinical relevance, there is no vaccine available for cryptococcosis. Several initiatives to generate artificial active immunity to prevent patients from developing this disease have been attempted including the development of a GXM bound to tetanus toxoid (Devi et al., 1991), a genetically engineered murine IFN- $\gamma$-producing cryptococcal strain (Wormley et al., 2007), and fungal components (Chaturvedi et al., 2014). Also, passive administration of antibodies has shown encouraging results in the laboratory (Casadevall et al., 1998). Nonetheless, although important 
insights have been acquired to better understand cryptococcosis, none of these initiatives have reached translational fruition. Thus, the development of alternative vaccination approaches is urgently needed.

Studies in mice with cell-mediated immunity deficiency support the importance of T-cells during cryptococcal infection given that these animals fail to mount T-dependent antibody responses (Graybill and Drutz, 1978; Cauley and Murphy, 1979). Conversely, thymus transplantation in these mice followed by fungal infection significantly prolongs survival (Graybill et al., 1979). Another piece of evidence supporting the role of T-cells in cryptococcal infection is that transference of T-cells from mice with cryptococcosis confers immunity to recipient mice (Lim and Murphy, 1980). In fact, the general consensus among medical mycologists is that it would be challenging to develop of an effective and protective anti-cryptococcal vaccine in individuals with impaired $\mathrm{CD}^{+} \mathrm{T}$ cell immunity, particularly in AIDS patients.

Rella et al., introduces a promising and innovative vaccination strategy to prevent cryptococcosis, by demonstrating that accumulation of sterylglucosides (SGs), a class of immunomodulatory glycolipids, in a genetically engineered non-pathogenic $C$. neoformans $(\Delta s g l 1)$ strain that lacks the sterylglucosidase enzyme and administered to mice preceding fungal infection confers complete protection in animals challenged with lethal doses of either C. neoformans or C. gattii (Rella et al., 2015). Rodents immunized with the $\Delta s g l 1$ strain a month prior to infection with wild-type cryptococci survived significantly longer than unexposed mice. Surprisingly, the $\Delta s g l 1$ strain induces a $\mathrm{CD}^{+} \mathrm{T}$ cells independent immunity since previous immunization to infection of immunocompromised mice completely protected these animals against cryptococcosis. SGs immune stimulation suggests the possibility that prevention and sustained protection may be achievable in the context of $\mathrm{T}$ cell deficiency possibly by other immune mechanisms. For instance, $\mathrm{CD}^{+} \mathrm{T}$ cells may compensate for the loss of $\mathrm{CD} 4^{+}$ $\mathrm{T}$ cells to facilitate protection against cryptococcosis in an IFN- $\gamma$-dependent manner (Lindell et al., 2005).

$\mathrm{B}$ cells play a critical role in protection against experimental cryptococcosis (Subramaniam et al., 2010; Szymczak et al., 2013). $\mathrm{T}$ cell independent immune responses result in the activation of $\mathrm{B}$ cells and the production of immunoglobulin M (IgM) which may be stimulated by SGs. For example, B-cell-deficient mice are susceptible to cryptococcal lung infection (Rivera et al., 2005), indicating an association between B cells and pulmonary inflammation control. In mice, IgM deficiency is linked with increased vulnerability to C. neoformans pulmonary

\section{REFERENCES}

Casadevall, A., Cleare, W., Feldmesser, M., Glatman-Freedman, A., Goldman, D. L., Kozel, T. R., et al. (1998). Characterization of a murine monoclonal antibody to Cryptococcus neoformans polysaccharide that is a candidate for human therapeutic studies. Antimicrobial Agents Chemother. 42, 1437-1446.

Cauley, L. K., and Murphy, J. W. (1979). Response of congentitally athymic (nude) and phenotypically normal mice to Cryptococcus neoformans infection. Infect. Immun. 23, 644 . infection and reduced phagocytosis, which can be restored by administration of IgM (Subramaniam et al., 2010). B cells from C. neoformans infected rodents produce fungal binding IgM and depletion of these cells resulted in impaired macrophage function facilitating cryptococcal dissemination to the brain (Rohatgi and Pirofski, 2012). Therefore, B cells might be SGs-glycolipid targets given that these humoral regulators enhance innate antifungal immunity via natural IgM, which promotes fungal containment in the lungs.

SGs have been shown to modulate cytokine production (Lee et al., 2007) suggesting their plausible implication in natural killer $\mathrm{T}(\mathrm{NKT})$ cell activation and macrophage polarization, innate immune responses that may be efficacious in prevention or treatment of cryptococcosis. NKT cells play an important role in the development of Th1 responses and host resistance to C. neoformans. For instance, NKT cells are increased in the lungs of mice infected with $C$. neoformans, associating the chemokine MCP-1 in their recruitment and accumulation (Kawakami et al., 2001a). Interestingly, glycolipid-activation of NKT cells increases IFN- $\gamma$ levels and fungal clearance suggesting another possible target cell for stimulation by the $\Delta$ sgl1 strain (Kawakami et al., 2001b). NKT cells also secrete IL-4, suggesting that this subset regulates both Th1- and Th2-polarization (Taniguchi et al., 2003). Likewise, the host response to $C$. neoformans in the lungs correlates with macrophage polarization (Davis et al., 2013), whereby M1 (classically activated) macrophages lead to Th1 responses (mainly IFN- $\gamma$ dominated) and M2 (alternatively activated) macrophages lead to Th2 responses. M1 macrophages kill cryptococci more effectively than M2 macrophages suggesting that SGs-mediated changes in the cytokine environment can influence macrophage polarization, with M1 macrophages augmenting host defense against C. neoformans.

Further studies focusing on the immune responses generated by SGs and safety issues associated with delivering live-attenuated cryptococci, heat-killed fungi, or vesicle formulations containing SGs preparations are necessary. However, these findings are significant in the setting of HIV/AIDS immune deficiency suggesting that the $\Delta s g l 1$ strain might provide a potential vaccination strategy against cryptococcosis. Rella et al., provide a proof of concept study that opens a novel area of research and a potential therapeutic strategy to prevent and reduce the devastating consequences of cryptococcosis.

\section{ACKNOWLEDGMENTS}

LRM is supported by NYIT COM Start-up Funds.
Chaturvedi, A. K., Hameed, R. S., Wozniak, K. L., Hole, C. R., Leopold Wager, C. M., Weintraub, S. T., et al. (2014). Vaccine-mediated immune responses to experimental pulmonary Cryptococcus gattii infection in mice. PLoS ONE 9:e104316. doi: 10.1371/journal.pone. 0104316

Davis, M. J., Tsang, T. M., Qiu, Y., Dayrit, J. K., Freij, J. B., Huffnagle, G. B., et al. (2013). Macrophage M1/M2 polarization dynamically adapts to changes in cytokine microenvironments in Cryptococcus neoformans infection. MBio 4:e00264-13. doi: 10.1128/mBio.00264-13 
Devi, S. J., Schneerson, R., Egan, W., Ulrich, T. J., Bryla, D., Robbins, J. B., et al. (1991). Cryptococcus neoformans serotype A glucuronoxylomannan-protein conjugate vaccines: synthesis, characterization, and immunogenicity. Infect. Immun. 59, 3700-3707.

Dromer, F., Varma, A., Ronin, O., Mathoulin, S., and Dupont, B. (1994). Molecular typing of Cryptococcus neoformans serotype D clinical isolates. J. Clin. Microbiol. 32, 2364-2371.

Goldman, D. L., Lee, S. C., and Casadevall, A. (1995). Tissue localization of Cryptococcus neoformans glucuronoxylomannan in the presence and absence of specific antibody. Infect. Immun. 63, 3448-3453.

Graybill, J. R., and Drutz, D. J. (1978). Host defense in cryptococcosis. II. Cryptococcosis in the nude mouse. Cell. Immunol. 40, 263.

Graybill, J. R., Mitchell, L., and Drutz, D. J. (1979). Host defense in cryptococcosis. III. Protection of nude mice by thymus transplantation. J. Infect. Dis. 140, 546-552. doi: 10.1093/infdis/140.4.546

Kawakami, K., Kinjo, Y., Uezu, K., Yara, S., Miyagi, K., Koguchi, Y., et al. (2001a). Monocyte chemoattractant protein-1-dependent increase of V alpha 14 NKT cells in lungs and their roles in Th1 response and host defense in cryptococcal infection. J. Immunol. 167, 6525-6532. doi: 10.4049/jimmunol.167. 11.6525

Kawakami, K., Kinjo, Y., Yara, S., Koguchi, Y., Uezu, K., Nakayama, T., et al. (2001b). Activation of Valpha14(+) natural killer $\mathrm{T}$ cells by alphagalactosylceramide results in development of Th1 response and local host resistance in mice infected with Cryptococcus neoformans. Infect. Immun. 69, 213-220. doi: 10.1128/IAI.69.1.213-220.2001

Lee, J. H., Lee, J. Y., Park, J. H., Jung, H. S., Kim, J. S., Kang, S. S., et al. (2007). Immunoregulatory activity by daucosterol, a beta-sitosterol glycoside, induces protective Th1 immune response against disseminated Candidiasis in mice. Vaccine 25, 3834-3840. doi: 10.1016/j.vaccine.2007.01.108

Levitz, S. M. (1991). The ecology of Cryptococcus neoformans and the epidemiology of cryptococcosis. Rev. Infect. Dis. 13, 1163. doi: 10.1093/clinids/13.6.1163

Lim, T. S., and Murphy, J. W. (1980). Transfer of immunity to cryptococcosis by Tenriched splenic lymphocytes from Cryptococcus neoformans-sensitized mice. Infect. Immun. 30, 5-11.

Lindell, D. M., Moore, T. A., McDonald, R. A., Toews, G. B., and Huffnagle, G. B. (2005). Generation of antifungal effector CD8+ T cells in the absence of CD4+ T cells during Cryptococcus neoformans infection. J. Immunol. 174, 7920-7928. doi: 10.4049/jimmunol.174.12.7920

Neilson, J. B., Ivey, M. H., and Bulmer, G. G. (1977). Cryptococcus neoformans: size range of infectious particles fro aerosolized soil. Infect. Immun. 17, 634.

Park, B. J., Wannemuehler, K. A., Marston, B. J., Govender, N., Pappas, P. G., and Chiller, T. M. (2009). Estimation of the current global burden of cryptococcal meningitis among persons living with HIV/AIDS. AIDS 23, 525-530. doi: 10.1097/QAD.0b013e328322ffac

Pettoello-Mantovani, M., Casadevall, A., Kollmann, T. R., Rubinstein, A., and Goldstein, H. (1992). Enhancement of HIV-1 infection by the capsular polysaccharide of Cryptococcus neoformans. Lancet 339, 21-23. doi: 10.1016/0140-6736(92)90142-P

Pettoello-Mantovani, M., Casadevall, A., Smarnworawong, P., and Goldstein, H. (1994). Enhancement of HIV type 1 infectivity in vitro by capsular polysaccharide of Cryptococcus neoformans and Haemophilus influenzae. AIDS Res. Hum. Retroviruses. 10, 1079-1087. doi: 10.1089/aid.1994.10.1079

Powderly, W. G. (1993). Cryptococcal meningitis and AIDS. Clin. Infect. Dis. 17, 837-842. doi: 10.1093/clinids/17.5.837

Rella, A., Mor, V., Farnoud, A. M., Singh, A., Shamseddine, A. A., Ivanova, E., et al. (2015). Role of Sterylglucosidase 1 (Sgl1) on the pathogenicity of Cryptococcus neoformans: potential applications for vaccine development. Front. Microbiol. 6:836. doi: 10.3389/fmicb.2015.00836

Rivera, J., Zaragoza, O., and Casadevall, A. (2005). Antibody-mediated protection against Cryptococcus neoformans pulmonary infection is dependent on B cells. Infect. Immun. 73, 1141-1150. doi: 10.1128/IAI.73.2.1141-1150.2005

Rohatgi, S., and Pirofski, L. A. (2012). Molecular characterization of the early B cell response to pulmonary Cryptococcus neoformans infection. J. Immunol. 189, 5820-5830. doi: 10.4049/jimmunol.1201514

Speed, B., and Dunt, D. (1995). Clinical and host differences between the two varieties of Cryptococcus neoformans. Clin. Infect. Dis. 21:28. doi: 10.1093/clinids/21.1.28

Subramaniam, K. S., Datta, K., Quintero, E., Manix, C., Marks, M. S., and Pirofski, L. A. (2010). The absence of serum IgM enhances the susceptibility of mice to pulmonary challenge with Cryptococcus neoformans. J. Immunol. 184, 5755-5767. doi: 10.4049/jimmunol.0901638

Szymczak, W. A., Davis, M. J., Lundy, S. K., Dufaud, C., Olszewski, M., and Pirofski, L. A. (2013). X-linked immunodeficient mice exhibit enhanced susceptibility to Cryptococcus neoformans infection. MBio 4:00265-13. doi: 10.1128/mBio.00265-13

Taniguchi, M., Harada, M., Kojo, S., Nakayama, T., and Wakao, H. (2003). The regulatory role of Valpha14 NKT cells in innate and acquired immune response. Annu. Rev. Immunol. 21, 483-513. doi: 10.1146/annurev.immunol.21.120601. 141057

Vecchiarelli, A. (2000). Immunoregulation by capsular components of Cryptococcus neoformans. Med. Mycol. 38, 407-417. doi: 10.1080/mmy. 38.6.407.417

Wormley, F. L. Jr., Perfect, J. R., Steele, C., and Cox, G. M. (2007). Protection against cryptococcosis by using a murine gamma interferonproducing Cryptococcus neoformans strain. Infect. Immun. 75, 1453-1462. doi: 10.1128/IAI.00274-06

Zaragoza, O., and Nielsen, K. (2013). Titan cells in Cryptococcus neoformans: cells with a giant impact. Curr. Opin. Microbiol. 16, 409-413. doi: 10.1016/j.mib.2013.03.006

Conflict of Interest Statement: The author declares that the research was conducted in the absence of any commercial or financial relationships that could be construed as a potential conflict of interest.

Copyright (c) 2015 Martinez. This is an open-access article distributed under the terms of the Creative Commons Attribution License (CC BY). The use, distribution or reproduction in other forums is permitted, provided the original author(s) or licensor are credited and that the original publication in this journal is cited, in accordance with accepted academic practice. No use, distribution or reproduction is permitted which does not comply with these terms. 